\title{
After the Asbo: Extending control over young people's use of public space in England and Wales
}

[April 2016 revision]

Published in Critical Social Policy 36(4) pp716-726, November 2016

\begin{abstract}
The concept of anti-social behaviour became prominent in the UK in the 1990s when the Labour government constructed it as an important policy challenge and deployed a series of high profile interventions against it. But anti-social behaviour faded significantly from the political agenda once Tony Blair's premiership ended in 2007 and its diminution appeared complete when the most high profile of interventions, the Anti-social Behaviour Order or Asbo, was replaced by the more mundane-sounding Injunction in 2014. This commentary argues, however, that far from the anti-social behaviour control regime softening as government priorities shifted elsewhere, legislation passed in 2014, allied to technological innovation, have increased the potential for those whose presence is considered problematic to be 'eliminated' from public spaces. This has particular significance for young people, whose discursive association with disorder and greater tendency to congregate in groups makes them likely to be the targets of enhanced exclusionary practices.
\end{abstract}

Key words: anti-social behaviour, dispersal, elimination, innovation, reform 


\section{Introduction}

Some of the most high profile - and controversial - domestic policy innovations associated with Britain's New Labour government during Tony Blair's premiership were those concerned with anti-social behaviour (ASB). Both the concept and the statutory measures designed to constrain such behaviour proved fertile ground for scholarship across a wide spectrum of academic disciplines. In this journal (see, for example, Fyson and Yates, 2011; Prior, 2009; Squires, 2006; Squires and Stephen, 2005) and countless others, what constituted ASB and the mechanisms introduced to suppress it was extensively debated, analysed and critiqued. Less heralded has been the winding up of this eventful first chapter of ASB control in England and Wales as the reforms set out in the Anti-Social Behaviour, Crime and Policing Act 2014 were implemented. This process was completed in March 2015 when the AntiSocial Behaviour Order (Asbo), arguably one of the most recognisable of New Labour's creations, became obsolete. Crucially though, the 2014 Act did not signal the demise of state intervention in ASB but what might be best described as a policy reboot. ASB governance version 2.0 may have a lower profile and be the subject of relatively little political rhetoric and public debate, but its powers remain pervasive. The objective of this commentary is to examine these developments and their implications for public space, a key site of perceived ASB.

The concept of ASB was largely absent from policy discourse until it was 'discovered' by New Labour in the mid 1990s (Squires, 2006). Disorderly conduct, incivilities, rowdy public behaviour and minor criminality, which were then low priorities for state institutions, were drawn together under the ASB banner. Echoing Wilson and Kelling (1982), New Labour argued that such behaviour had both a significant impact on quality of life in residential neighbourhoods and, if ignored, could spiral into more serious criminality (Home Office, 2003). Concerted state intervention was the prescribed cure. The political rhetoric and legislative activity surrounding ASB built inexorably as Tony Blair and his Home Secretaries passionately advocated deploying the coercive power of the state to improve quality of life and rebuild respect (Blair, 2010). But following Blair's resignation as Prime Minister in 2007 the rhetoric became less shrill, the use of the Asbo rapidly declined (Ministry of Justice, 2014), and government priorities shifted elsewhere. Aided also by a sharp fall in crime over the last decade to levels not witnessed in the UK since the early 1980s, the public profile of ASB has ebbed. 
Given the gradual fading of ASB from the post-Blair political agenda, it is perhaps surprising that the 2010-15 Conservative-Liberal Democrat Coalition government should choose to revisit this domain of policy. However, the Coalition was arguably as committed to instilling dutiful and responsible citizenship as its predecessor (Little, 2015). It also asserted that reform was necessary to rationalise the complex web of provision it had inherited, to improve the questionable effectiveness of some Blair-era measures and to make them more responsive to local need (Home Office, 2012). The 2014 legislation notably widened the scope of some extant measures and introduced a number of new provisions specifically targeted at behaviour in public space. The old system of ASB control was especially controversial for its deployment against the everyday activities of young people (Bannister and Kearns, 2012; Bell, 2014; Crawford, 2009a; Woolley, 2009), bringing them into early contact with the criminal justice system. Its post-2014 incarnation shows every sign of extending these proscriptions. Indeed, allied to other recent innovations designed to clear young people from public space, ASB governance 2.0 appears to chime with both the 'eliminative ideal' outlined by Rutherford (1997) and recent US policies facilitating 'banishment' of the problematic (see, for example, Beckett and Herbert, 2010).

\section{Anti-social Behaviour: the road to 2014}

In order to understand the impact of 2014's reforms, a brief recap of the original ASB controls created during Tony Blair's premiership (1997-2007) is necessary. Through the Crime and Disorder Act 1998 and the Anti-Social Behaviour Act 2003, his Labour governments legislated to create new mechanisms to curb ASB in England and Wales ${ }^{\mathrm{i}}$. Many were controversial hybrids of civil and criminal law which allowed restrictions to be imposed on behaviour not in itself illegal. Recipients of one of the new orders who continued the activity from which they were banned became subject to criminal penalty due to breach of the conditions imposed upon them: their crime was, in essence, the failure to respond appropriately to enforcement action. The behaviour targeted by new powers was left open to very considerable local interpretation, a non-specific definition of ASB allowing a wide sweep of activities, from the already criminalised to very minor nuisance, to attract an intervention from the authorities if it could be shown that the behaviour "caused or was likely to cause harassment, alarm or distress to one or more persons not of the same household" (Crime and Disorder Act, 1998 s.1). 
Amongst the interventions created by legislation, only the Child Curfew Order was explicitly targeted at young people. The remainder could be deployed against all perpetrators of acts deemed anti-social and there can be no doubt that many adults have been subject to their interdictions. Nonetheless, young people, at least in England and Wales, became a privileged target of ASB control mechanisms, reflecting concerns about their activities, their high visibility in public space and the normative association of groups of children with deviance, which became entrenched in the 1990s and 2000s (Brown, 2013; Squires, 2006). Crucially, children control no private space of their own and are dependent on access to indoor space belonging to others, such as parents, schools and youth clubs. As a consequence, they make use of - and are more visible in - public space than many other social groups (Pickering et al, 2012). This is especially so in deprived communities where opportunities to engage in indoor leisure activities may be limited, making public space prime social space (Brown, 2013; Woolley, 2009). This visibility coupled with popular and political discourses casting deprived communities as feckless, anti-social and lacking discipline (Jones, 2012) ensured that certain young people found themselves in a precarious situation.

The two pre-2014 ASB control mechanisms with the greatest consequences for young people's use of public space were arguably the flagship Asbo and the Dispersal Order. Imposed by the courts in response to evidence of sustained ASB, Asbos were designed to act as a deterrent to its recurrence. During the period 2000 to 2013,36\% of all Asbos were issued to juveniles under the age of $18,93 \%$ of them to males (Ministry of Justice, 2014) ${ }^{\mathrm{ii}}$. Recipients were usually required to desist from specified behaviour for the duration of the Order, a minimum of two years. Additional conditions could be attached requiring them not to fraternise with named individuals and to avoid defined geographic areas. These could range from single streets to entire neighbourhoods. Concerns have been raised that such prescriptive conditions can impede everyday activities such as visiting friends and relatives or accessing services and, as a consequence, may be setting juveniles up to fail (McIntosh, 2008). Significantly, the conditions set out in $68 \%$ of Asbos issued to juveniles between 2000 and 2013 were found in court to have been breached at least once (Ministry of Justice 2014). Breach attracts criminal penalty and $37 \%$ of juveniles in breach of Asbo conditions 20002013 received custodial sentences (Ministry of Justice 2014).

The Asbo at least required the recipient to possess a track record of proven 'anti-social' conduct. The Dispersal Order, in contrast, was more concerned about the presence in public 
space of those considered to pose a threat to 'good order'. In geographic areas designated by police and municipal authorities as Dispersal Zones, the police were empowered to disperse groups of two or more people if there was a possibility that their continued presence in that space may cause harassment, alarm and distress to others at some point in the future. Failure to comply with direction to leave was a criminal offence as could be returning to the Dispersal Zone inside 24 hours. Research on Dispersal Orders has found that their de facto targets are young people (see, for example, Crawford 2009a), whose 'hanging around' is viewed as a nuisance in itself and a potential precursor to more serious disorder. Presence in numbers rather than observed behaviour becomes the marker of deviance and a trigger for intervention (Bannister and Kearns, 2012). Indeed, Flint and Smithson's (2007) research in Manchester found that enforcing Dispersal Zones earned the police the nickname 'child catchers'. Inevitably, the targeting of groups means certain public spaces risk becoming off-limits to individuals who engage in no unlawful or disorderly behaviour themselves but are simply damned by age, association with others and unwelcome presence.

\section{Anti Social Behaviour control: version 2.0}

The Anti-Social Behaviour, Crime and Policing Act 2014 repealed most of the ASB control mechanisms designed by Labour and replaced them with a new toolbox of measures. ASB policy may lack the profile it enjoyed in the mid 2000s but the changes outlined in the draft legislation still attracted controversy. In particular, the proposed replacement for the Asbo, the Injunction to Prevent Nuisance and Annoyance or IPNA, was to be available to the civil courts as a response to conduct or the threat of conduct "capable of causing nuisance or annoyance to any person" "iii . Critics argued that inserting this wording in place of the longstanding "causing or likely to cause harassment, alarm and distress" lowered the threshold of what constituted ASB. This could lead to many individuals being caught up in the web of ASB controls for behaviour which, whilst annoying, should not be proscribed by the state (The Guardian, 2014). Following a defeat on an amendment to this wording in the House of Lords, the Coalition government agreed to revise the bill: the "nuisance or annoyance" clause for IPNAs sought to quell ASB in dwellings was retained, but "harassment, alarm and distress" was reinstated as the basis for intervention in ASB in all other spaces through a new Injunction. 
The Injunction itself differs from the Asbo in a number of ways. Most significantly, it is a wholly civil injunction ${ }^{\text {iv }}$. While this means applications are subject to the civil ("on the balance of probability") rather than criminal burden of proof, which may erode some safeguards, a breach constitutes contempt of court rather than a defined criminal offence. The maximum punishment for failing to adhere to the conditions of an Injunction is two years' imprisonment for adults and a three-month detention order for teenagers aged 14 to 17 (Home Office, 2013a; Strickland et al, 2013). In contrast, the maximum penalty for breach of an Asbo is a five year prison sentence for adults and 24 month Detention and Training Order for young offenders. Moreover, an Asbo was imposed for a minimum of two years and could remain in place 'until further order'. No such minimum is prescribed for Injunctions but the duration of the order must be stated and, when the recipient is under 18 years old, this must be no longer than one year.

Amongst the other reforms, those of particular relevance here are new dispersal powers, the Public Space Protection Order and the Community Trigger. The legislation gives the police (and Police Community Support Officers where designated) "the power to disperse individuals or groups causing or likely to cause ASB in public places" (Home Office, 2013b, para 2) and require them to stay away from a specified area for up to 48 hours. Prior designation of a Dispersal Zone is no longer required in order for police to acquire these powers, just the agreement of an officer of the rank of Inspector that dispersal is appropriate. An Inspector is permitted to preemptively designate an area, where dispersal powers will apply for up to 48 hours, whenever the need to use the powers is expected to arise; no previous evidence of ASB in the area selected is required. As well as to leave an area, officers are also empowered to "direct the person to surrender any item which they reasonably believe has been, or might be, used in behaviour that alarms, harasses or distresses" (Strickland et al, 2013: 29). The penalty for non-compliance with the direction to leave an area remains the same as for the old Dispersal Order: a criminal conviction and, for adults, up to three months' custody and/or $£ 2500$ fine.

Additional control over ASB in communal spaces is promised by the Public Space Protection Order (PSPO) which permits a local authority, in consultation with the police and its Police and Crime Commissioner, to impose conditions on the use of designated public spaces in order to prevent the continuation of specified behaviour deemed detrimental to quality of life in the area (Home Office, 2013c). An Order lasts for up to three years and can be renewed 
before expiration. Like the Asbo it is a hybrid order meaning breach is a criminal offence attracting, in this case, a fixed penalty notice or larger fine on summary conviction. Finally, through the Community Trigger, the legislation empowers complainants to force the police, local authorities and other bodies to act on their reports of persistent ASB. If no resolution has been found for ongoing or recurring ASB, the victim or someone acting on their behalf can trigger a case review, requiring the authorities to revisit their response and, where appropriate, develop an action plan.

It is far from clear what impact these many reforms will have on either young people or their use of public space. In their response to the 2014 Bill as originally worded, the civil liberties organisation Big Brother Watch observed:

The boundaries between youthful exuberance and antisocial behaviour appear to be growing ever more blurred, and we are concerned that the Bill does not place any weight on the intent of those concerned. It is important to avoid a sense that the law is "against" young people and this legislation in its current form lacks the safeguards to ensure over-zealous enforcement does not become the norm (Big Brother Watch 2013 cited in Strickland et al 2013, 15).

Making dispersal powers quickly applicable to any area appears to give rise to the possibility that young people may find themselves moved on from a larger number of (constantly shifting) geographic areas on the basis of the risk signalled by their presence, rather than due to their prior participation in any ASB. That said, amongst its guides to the Bill, the Home Office (2013d) published a document expressly addressing the question "When is hanging around anti-social?" It acknowledges that young people collect in groups for safety or to socialise and that intolerance of them can be due to the sense of unease their presence may generate. Emphasis is given to the importance of assessing whether their behaviour is genuinely anti-social and only deploying a criminal justice intervention as a last resort. However, since ASB legislation grants "the anxious, uncertain [adult] individual... definitional primacy in their assessment of anti-social behaviour" (Bannister and Kearns $2012,390)$ and the guidance includes hard to define problems such as "excessive noise" as an indicator of $\mathrm{ASB}$, it is far from certain that a consistent nationwide approach to the spatial practices of young people will be pursued. The Public Spaces Protection Order (PSPO) also allows significant restrictions to be imposed on the use of public space. Early indications suggest that it is being deployed against a wide range of street activities associated with the 
homeless and young people (Liberty 2015). Moreover, in what is probably an attempt to reduce the displacement of unwanted activity associated with the old Dispersal Zones (Moore and Scourfield 2005), PSPOs are being imposed on entire urban areas rather than affected sub-districts.

\section{Eliminating problem youth from public space}

The strengthening of powers to rid certain spaces of those who symbolise disorder, regardless of the behaviour they are engaged in, appears to fit into a broader trend towards elimination and exclusion. Government-led remedies to ASB have been supplemented during the last decade by a market-driven innovation, the Mosquito Anti-loitering Device, which specifically targets the activities or, more precisely, the presence of young people. It is designed to address "the eternal problem of unwanted gatherings of youths and teenagers in shopping malls, around shops and anywhere else they are causing problems" (Compound Security, n.d. cited in Walsh, 2008). It is a small device, easily mounted to the outside wall of a building, which emits a high frequency tone usually only audible to young people, whose hearing is sufficiently sensitive to detect it. The tone is irritating enough that those exposed to it will usually move out of range within a few minutes. Its objective is to discourage groups of teenagers from congregating in certain spaces or to disperse those who are already present in a zone where they are not welcome. The manufacturers suggest that, once aware of the presence of one of these devices, young people will avoid that location in the future.

Concerned about the implications of the Mosquito, the UK's Children's Commissioners (2008) launched the Buzz Off campaign to discourage its use and press for regulation. The Council of Europe (2010) recommended that its use in public places should be outlawed, while Little (2015) argues that it breaches both human rights and equalities legislation. He also suggests that, in causing harassment and distress to young people,the device itself is antisocial. However, the UK government has opted not to regulate the Mosquito at all. Since it is freely available to purchase on the open market it is difficult to be certain how many are currently in use and in what contexts. Little (2015) reports that 9000 were in operation in the UK in 2012. Testimonials on the manufacturer's website (compoundsecurity.co.uk) indicate purchasers include shopkeepers, municipal authorities, the police and householders. 
The dispersal of young people for being in the wrong place at the wrong age can be read as further evidence of an "eliminative ideal" underpinning aspects of contemporary criminal justice. To Rutherford (1997: 117), elimination aims "to solve present and emerging problems by getting rid of troublesome and disagreeable people with methods that are lawful and widely supported" (see also Moore and Scourfield, 2005). Britain is not alone in pursuing the elimination from public space of problem populations, but its privileging of young people is unusual. Research on Seattle, one of a number of US cities to have adopted crime-related zoning laws over the last decade (Herbert and Beckett, 2009; Beckett and Herbert, 2010), has examined the demarcation of a mixture of publicly and privately owned city spaces from which those convicted of a wide set of offences are automatically banned. The offence for which a banned individual was originally prosecuted is perceived to mark them as a risk and this is considered justification for excluding them from spaces where opportunities to reoffend may be high. Simply being discovered in a zone from which one is banned can lead to arrest and prosecution. Whilst the targets of Seattle's zoning laws are the homeless and those convicted of drug and prostitution-related offences, the decoupling of the right to intervene and punish from the need to witness any new criminal or anti-social behaviour appears to very much parallel developments in Britain.

\section{Conclusion}

In 2015 ASB had faded so much from political discourse in the UK that it was almost a footnote in the manifestos of the main political parties at the General Election. Yet the Antisocial Behaviour Crime and Policing Act 2014 made significant reforms to mechanisms of ASB control that apply in England and Wales. The powers already enjoyed by the police, courts, municipal authorities and social housing providers were extended. Provision was also specifically made to impose greater control over the use of public space via the new Public Spaces Protection Order and enhanced dispersal powers. Parallel innovation in the technological sphere, specifically the Mosquito anti-loitering device, further constrain young people's usage of urban public space (Little 2015) - space that is often close to home rather than part of any commercially significant downtown core. Some whose spatial practices are curtailed will first be found guilty of engaging in behaviour deemed anti-social. Others, however, are likely to be excluded either because their age and propensity to socialise in public with their peers is considered likely to lead to disorder in the future or because the act of 'hanging out' in and of itself is viewed as an unwelcome nuisance (Pickering et al, 2012). 
Crucially, the crude identification of groups or specific segments of the population as potentially problematic means no attempt is made to distinguish between members acting or most likely to act anti-socially and the rest. This is particularly so in the case of the Mosquito, a "sonic obstacle" (Little, 2015: 179) to young people's access to public space. There appear to be parallels here with the use of banishment as a means of social control elsewhere, notably in the USA, as policy becomes geared around an 'eliminative ideal' (Rutherford, 1997).

The most regressive elements of pre-2014 ASB governance in England and Wales, many of which have not been diluted by reform, spurred the United Nations Committee on the Rights of the Child (UNCRC) $(2010,66)$ to express concern "at the restriction imposed on the freedom of movement and peaceful assembly of children" by legislation and technology, with the committee strongly recommending the UK government reconsider these measures. The Asbo's role in ensnaring young people in the criminal justice system may have been somewhat attenuated by its replacement in the 2014 Act with the Injunction, since breach is no longer a criminal offence. However, the wider concerns raised by the UNCRC, which reinforced those expressed by the European Commissioner for Human Rights three years earlier (Gil-Robles, 2005), persist. The difference now is that ASB control has become normalised and debate much more muted.

\section{References}

Bannister J and Kearns A (2012) Overcoming intolerance to young people's conduct: Implications from the unintended consequences of policy in the UK. Criminology \& Criminal Justice 13(4): 380-397.

Beckett K and Herbert S (2010) Penal boundaries: Banishment and the expansion of punishment. Law \& Social Inquiry 35(1): 1-38.

Bell E (2014) The anti-sociality of anti-social behaviour policy. In: Pickard S (ed) Anti-Social Behaviour in Britain. Basingstoke: Palgrave Macmillan pp. 225-236.

Blair T (2010) A Journey. London: Hutchinson.

Brown D (2013) Young people, anti-social behaviour and public space: The role of community wardens in policing the 'ASBO generation'. Urban Studies 50(3): 538-555.

Crawford A (2009a) Criminalizing sociability through anti-social behaviour legislation: Dispersal powers, young people and the police. Youth Justice 9(1): 5-26. 
Crawford A (2009b) Governing through anti-social behaviour: Regulatory challenges to criminal justice. British Journal of Criminology 49(6) 810-31.

Flint J and Smithson H (2007) New governance of youth disorder: a study of local initiatives. In: Atkinson R and Helms G (eds) Securing an Urban Renaissance. Bristol: The Policy Press. 165-182.

Fyson R and Yates J (2011) Anti-social behaviour orders and young people with learning disabilities. Critical Social Policy 31(1): 102-125.

Gil-Robles A (2005) Report by Mr Alvaro Gil-Robles, Commissioner for Human Rights, on his visit to the United Kingdom, $4^{\text {th }}-12^{\text {th }}$ November 2004. Strasbourg: Council of Europe.

Herbert S and Beckett K (2009) Zoning out disorder: Assessing contemporary practices of urban social control. Studies in Law, Politics and Society 47: 1-25

Home Office (2003) Respect and Responsibility - Taking a Stand Against Anti-Social Behaviour. London: The Stationery Office.

Home Office (2012) Putting Victims First: More Effective Responses to Anti-Social Behaviour. London: The Stationery Office.

Home Office (2013a) Fact sheet: Replacing the Asbo. Available at:

https://www.gov.uk/government/uploads/system/uploads/attachment_data/file/251312/01_Fac tsheet_Replacing_the_ASBO_-_updated_for_Lords.pdf (accessed 2 April 2015)

Home Office (2013b) Fact sheet: Dispersal Powers. Available at:

https://www.gov.uk/government/uploads/system/uploads/attachment_data/file/202891/Fact_s heet_Police_Powers.pdf (accessed 2 April 2015)

Home Office (2013c) Fact sheet: Environmental Anti-Social Behaviour. Available at:https://www.gov.uk/government/uploads/system/uploads/attachment_data/file/251313/01_ Factsheet_Environmental_ASB_-_updated_for_Lords.pdf (accessed 2 April 2015)

Home Office (2013d) Reform of anti-social behaviour powers: Groups 'hanging around'. Available at:

https://www.gov.uk/government/uploads/system/uploads/attachment_data/file/248750/01_GR OUPS_HANGING_AROUND_WEB.PDF (accessed 2 April 2015)

Jones O (2012) Chavs: the demonization of the working class. London: Verso.

Liberty (2015) Campaigning against: Public Space Protection Orders. Available at: www.liberty-human-rights.org.uk/campaigning/public-space-protection-orders-0

Little C (2015) The 'Mosquito' and the transformation of British public space. Journal of Youth Studies 18(2): 167-182

McIntosh B (2008) ASBO youth: Rhetoric and realities. In: Squire P (ed) ASBO Nation: The Criminalisation of Nuisance. Bristol: The Policy Press, pp. 236-256. 
Ministry of Justice (2014) Statistical Notice: Anti Social Behaviour Order (ASBO) Statistics England and Wales 2013. Available at:

https://www.gov.uk/government/uploads/system/uploads/attachment_data/file/355103/antisocial-behaviour-order-statistical-notice-2013.pdf

Moore S and Scourfield P (2005) Eliminating the visible: Exploring community responses to anti-social behaviour. Crime Prevention and Community Safety 7(3): 51-61

Pickering J, Kintrea K and Bannister J. (2012) Invisible walls and visible youth: Territoriality amongst young people in British cities. Urban Studies 49(5): 945-960.

Prior D (2009)The 'problem' of anti-social behaviour and the policy knowledge base: Analysing the power/knowledge relationship. Critical Social Policy 29(1): 5-23.

Rutherford A (1997) Criminal policy and the eliminative ideal. Social Policy and Administration 31(5): 116-135.

Squires P (2006) New Labour and the politics of anti-social behaviour. Critical Social Policy 26(1): 144-168.

Squires P and Stephen D (2005) Rethinking ASBOs. Critical Social Policy 25(4): 517-528.

Strickland P et al (2013) Anti-social Behaviour, Crime and Policing Bill, Research Paper 13/34. London: House of Commons Library.

The Guardian (2014) Lords reject government's antisocial, crime and policing bill. 9 January

UNCRC (2010) Report on the forty-ninth session, 15 September - 3 October 2008. Geneva: United Nations.

UK Children's Commissioners (2008) UK Children's Commissioners' Report to the UNCRC. Available at: http://www.childrenscommissioner.gov.uk/publications/uk-childrenscommissioners-report-un-committee-rights-child

Walsh C (2008) The Mosquito: A repellent response. Youth Justice 8(2): 122-133

Wilson JQ and Kelling G (1982) Broken windows: The police and neighbourhood safety. The Atlantic, 1 March. Available at:

http://www.theatlantic.com/magazine/archive/1982/03/broken-windows/304465

Woolley H (2009) Every child matters in public open space. In: Millie A (ed) Securing Respect: Behavioural Expectations and Anti-Social Behaviour in the UK. Bristol: The Policy Press, pp. 97-115.

\footnotetext{
${ }^{\text {i }}$ Separate ASB legislation relating to Scotland was passed in 2004. The ASB provisions of the 2014 Act only apply to England and Wales.

${ }^{\mathrm{ii}}$ The ethnicity of Asbo recipients is unknown as this data was not systematically collected.

${ }^{\text {iii }}$ Social housing providers needed to prove this in order to secure an Anti-Social Behaviour Injunction on adult tenants under the original ASB legislation.
} 
${ }^{\text {iv }}$ From 2005 an Asbo 'on conviction' or Crasbo could be part of a criminal court sentence. The 2014 Act replaced this with the Criminal Behaviour Order, a completely separate entity to the Injunction. 